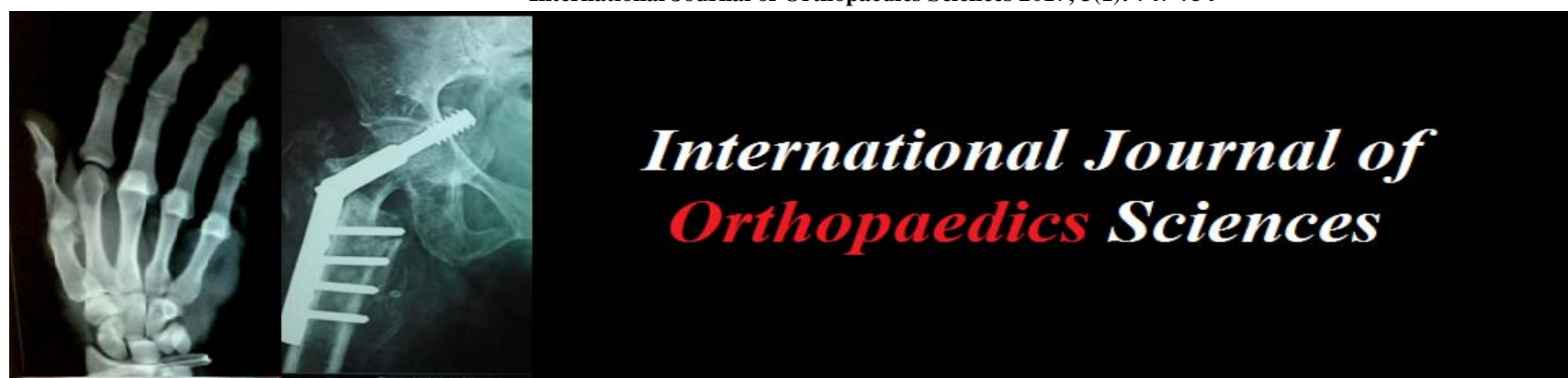

ISSN: 2395-1958

IJOS 2017; 3(1): 747-754

(C) 2017 IJOS

www.orthopaper.com

Received: 20-11-2016

Accepted: 21-12-2016

Dev Krishan Sharma Resident, Department of Orthopaedics, Unique Super Speciality Centre, Indore, Madhya Pradesh, India

Murtuza Rassiwala Resident, Department of Orthopaedics, Unique Super Speciality Centre, Indore, Madhya Pradesh, India

Pramod P Neema HOD, Department of Orthopaedics, Unique Super Speciality Centre, Indore, Madhya Pradesh
Correspondence Murtuza Rassiwala Resident, Department of Orthopaedics, Unique Super Speciality Centre, Indore, Madhya Pradesh, India

\section{Navigation assisted total knee arthroplasty - Evaluation of correction of clinico - Radiololgical parameters in substantial varus deformity}

\author{
Dev Krishan Sharma, Murtuza Rassiwala and Pramod P Neema
}

DOI: http://dx.doi.org/10.22271/ortho.2017.v3.i1k.110

\section{Abstract}

Background: In the present scenario arthritis of knee joint is inevitable. Total- knee replacement is the final solution in severely deformed joints for pain free mobility. Longevity of the replaced joint is mainly dependent on good mechanical alignment. The navigation system was introduced with a claim to achieve near normal parameters of weight bearing axis thereby increasing the life of implanted knee.

Material and Method: This was a prospective study from January 2012 to August 2015 done in Department of Orthopaedics at our institute. A cohort of 20 patients were taken with varus deformity more than 15 degree and operated with the help of navigation system. The result were compared with a cohort of 20 patients suffering from more than 15 degree varus deformity and operated without navigation. Informed consent was taken. Clearance from ethical committee of the institute was taken. Patients were evaluated pre operatively and post operatively at $1,3,6$ and 12 months post operatively with the help of knee society knee score and function score and radiographically.

Results: Using computer assisted navigation and measured resection technique of ligament balancing in total knee replacement, mean tibio-femoral angle of 16.40 degrees varus preoperatively (range, 15degrees -24 degrees) was corrected to 2.4 degrees varus (range 5 degree valgus- 4 degree varus) postoperatively. Mean Knee Society score improved from 23.4 (range 0-44) to 86 (range 72 -98), and function score from 21 (range, 0-46) to 98.50 (range 55-100) at 12 months (range 12 month -34 months). No patient reported significant instability. Correction of severe varus deformity by the technique reported can successfully restore alignment, pain free motion, and stability.

Conclusion: Substantial Varus knee deformity is very well corrected when total knee arthroplasty is done with the help of navigation system. Here, in our study, either no varus or residual varus deformity was 1-2 degree. Navigation system assisted surgery produces good functional outcome and near normal radiological parameters.

Keywords: TKR, navigation, varus, arthroplasty, CAS, TKA

\section{Introduction}

Knee pathology and especially total knee replacement (TKR) have been the focus of research over the last ten years with controversy still existing regarding best practice for the treatment of the degenerative joint ${ }^{(1)}$. The prevalence of knee arthritis in the population is significant and has been estimated as two to ten percent for men and one and a half to fifteen percent for women ${ }^{[2,3]}$.

Total knee replacement, is a highly successful surgical procedure which involves replacement of all three compartments of the knee -the medial compartment, the lateral compartment and the patello femoral compartment. Longevity of the implanted joint is mainly dependent on good mechanical alignment.

To improve precision of implant positioning, various mechanical alignment guides are used, both intramedullary and extramedullary, but technical errors with these conventional surgical techniques still occur.

Computer assisted navigation surgery (CAS) has been performed in total knee arthroplasty (TKA) for approximately 10 years. This technique offers experienced and inexperienced surgeons improved control and reproducible results.

During the last decades CAS instrumentations have been improved in accuracy and various studies have been made to analyse results using this technique in TKA surgery. 
Advocates of this technique in total knee replacement claim benefits in terms of improving accuracy for alignment of the leg and orientation of the components, as well as a reduction in blood loss and a lower rate of intracranial micro emboli compared with traditional surgery.

The survival rate for modern total knee arthroplasty is reported between $80 \%$ to $95 \%$ after $10 y$ ears of follow up ${ }^{[4,5]}$. The most important factorof failure is malalignment of mechanical axis $[6,7]$. However, no clear published results are available associated with superior clinical and patients perceived functional results and consequently longer survival rate ${ }^{[8]}$.

Computer-assisted navigation seems to be helpful in those difficult situations where accurate alignment remains crucial but traditional instrumentation is not applicable. Traditional cutting guides during knee arthroplasty relies on intramedullary (IM) femoral instruments and either intramedullary or extramedullary (EM) tibial instruments to obtainproper axial alignment.

Intramedullary instruments cannot be used in patients with:

- Retained hardware that would be difficult or inadvisable to remove or longstemmedhip implants that could obstruct introduction of long IM instruments.

- Severe posttraumatic extrarticular femoral deformity when one is unable to pass an IM guide to accurately make a distal femoral cut.

- IM guides may increase the infection risk in patients with history of focal diaphyseal osteomyelitis around the knee joint ${ }^{[9]}$.

- Patients with severe cardiopulmonary disease or a history of patent foramen ovale who maybe at risk for embolic dissemination because of femoral IM instrumentation ${ }^{[10]}$.

These problems can be avoided with Computer-assisted navigation.

Varus deformity can be classified as intra or extra articular. There have been several studies to define what a "severe" varus is. Ritter et al in 2004 defined massive varus as a tibiofemoral angle of more than or equal to 20 degrees ${ }^{[11]}$. In a similar study in 2005, Mullaji AB et al also defined severe varus deformity as more than or equal to 20 degrees of tibio femoral angle ${ }^{[12]}$. Recently, a new classification for the severity of arthritic disease was proposed using simple semantic terms that will allow surgeons to compare deformities in the near future. Mechanical alignment within $3^{0}$ was considered normal and a deformity within $4-10^{\circ}$ acommon deformity. With increments of $10^{\circ}$, the classification considers 11-20 a substantial deformity, $21-30^{\circ}$ an important deformity, and $>30^{\circ}$ an extreme deformity ${ }^{[13]}$.

The Hospital for Special Surgery Rating System (HSS) ${ }^{[14]}$ and the Knee Society Clinical Rating System (KSS) ${ }^{[15]}$ are the two most widely used scoring systems for the evaluation of the outcome of knee arthroplasty.

KSS has become the standard tool for the clinical evaluation and reporting of the results of TKA surgery. Most major journals in this field of study strongly encourage the use of the KSS score as an evaluation tool so that qualified information would be available on the outcome and to enable a comparison of different studies. The KSS system deals separately with the status of the operated knee and the function score of the patient, which solves the problem with interference by comorbid conditions. The Knee Score consists of scores for pain, range of motion and stability in both the coronal and sagittal planes, with deductions for fixed deformities and extensor lag.

The Function Score consists of scores for the ability to walk on a level surface and to ascend and descend stairs, with deductions for the use of external supporting devices. These two subscales of KSS are usually recorded separately as two scores, the KSS Knee Score and KSS Function Score, rather than as one summation score.

\section{Material and Method}

Aim of this study was to assess correction of clinical and radiological parameters; to evaluate accuracy and efficacy of results obtained in navigation assisted Total Knee Arthroplasty in patient suffering from severe varus knee deformity.

This was a prospective study from January 2012 to August 2015 done in Department of Orthopaedics at our institute with a minimum follow up period of 12 months (range 12-34 months). A cohort of 20 patients were taken with varus deformity more than 15 degree and operated with the help of navigation system. The result were compared with a cohort of 20 patients suffering from more than 15 degree varus deformity and operated without navigation.

The two groups were matched for age, sex, deformity and mean knee society knee score and function score and the type of implant used.

\section{Inclusion criteria}

1. varus knee deformity more than 15 degree.

2. Age less than 75 years.

\section{Exclusion criteria}

1. Patients suffering from valgus deformity and varus less than 15 degree.

2. Age $>75$.

3. Hip and ankle pathologies.

4. Old fractures of tibia/femur with implant in situ.

5. Ongoing infection of knee joint.

\section{Knee Society Knee Score \\ Pain score (0-50) \\ Range of motion (5 degrees $=1$ point) \\ Stability \\ Medio lateral ( $0-15$ points) \\ Antero-posterior (0-15 points)}

\section{Deductions}

Malalignment (range 0 to -20 points)

Flexion contracture (-2/-5/-10/-15 points)

Extensor lag (-5/-10/-15 points)

\section{Function Score (0-100 points)}

Walking (0-50 points)

Stairs (0-50 points)

\section{Deductions}

Cane/walker (range 0 to -20 )

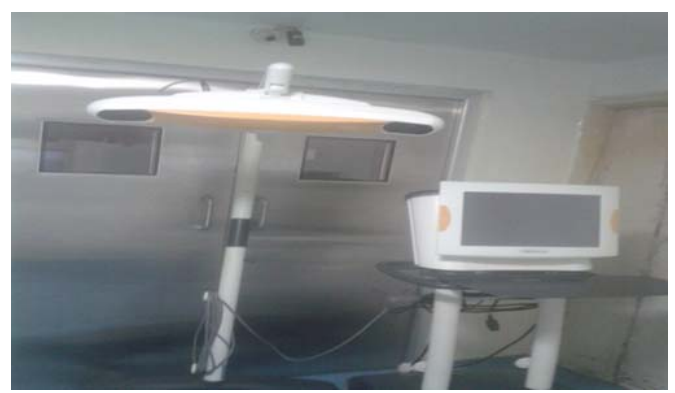

CAS is the solution for sever varus 


\section{Outcome measures}

1. Clinical- Pain, Knee Range of motion, Flexion, Residual varus deformity.

2. Functional - Knee society knee score.

3. Radiological- Limb alignment assesed with navigation intra op, immediate post-operative and follow up at 1 month, 3 month, 6 month, 1 year with $\mathrm{x}$ rays.

\section{Operative procedure}

All patients were operated by anterior midline incision. Joint was approached through the medial parapatellar capsular approach extended proximally to the inferior margin of the rectus femoris and distally to the medial margin of the tibial tubercle. The medial side of the knee was exposed by subperiosteally stripping the anteromedial capsule and deep medial collateral ligament off the tibia to the posteromedial corner of the knee.

Patella was then everted laterally with knee in extension. If needed, lateral patella femoral plicae release and release of adhesions was done. ACL along with both menisci were excised. Then tibia was subluxated anteriorly and externally rotated.

Release of the medial structures (superficial and deep parts of medial collateral ligament, semi-membranous tendon, pes anserinus and part of posterior capsule) as per demand in the individual case was done. All osteophytes were removed.

\section{Anatomy Registration In navigation system Determination of Femoral head center}

Hip joint center is identified by circumduction of the hip with hip and knee flexed. The software geometrically produces the center of femoral head within $1 \mathrm{~mm}$ of accuracy. This is the most accurate way of identifying the center of rotation of the femoral head.

\section{Distal Femur Mapping}

We determined the center of femur and femoral Antero posterior axis at first. For the femoral Antero posterior axis (white side's line), the pointer's axis was aligned with the most anterior point of the intercondylar groove.

\section{Proximal Tibia Mapping}

The center of tibial plateau and antero posterior axis are also marked digitalized.

\section{Determination of the center of the ankle}

The medial and lateral malleolus are digitalized and computer determines the center of ankle as a reference for the anatomic axis of the tibia and the mechanical axis of the limb.

The computer then gives the information regarding the orientation of bony cuts, implant sizing and soft tissue tension

\section{Implementation and verification}

The essential components after registration are setting up of the cutting blocks and rechecking of the cuts. The alignment is confirmed on the computer screen. The hardware used is similar in most systems. The computer receives the information from an infrared camera. This in turn transfers signals from the beacons fixed to the patient. The computer screen provides the visual images required for the surgery. The software provides a structural model which provides interactive images and allows storage of data that describe the surgery.
The next step is to determine the component-to-component position and soft tissue balance, which in turn help in analysing the radiological and clinical outcomes

Bone cuts were made using appropriate jigs. Tibial preparations was followed by femoral. Three degrees of posterior slope was maintained while making tibial cut.

Patellar resurfacing was done in all TKR following removal of peripheral osteophytes. Patellar tracking over the femoral component was ascertained. Trial components were then fixed. Stability and range of movement was rechecked in extension and flexion.

\section{Technique of ligament balancing}

Two popular knee replacement techniques currently practiced are "measured resection" and "balanced resection."Both incorporate ligament balancing during the operation, but with differing emphasis. In both techniques osteophytes are removed as the initial stage of achieving a balanced knee.

We used the "measured resection" technique:-

It involves performing the bone cuts and trialing the prosthesis before ligament balancing is undertaken. The basic principle is to resect a measured amount of bone from both the distal femur and proximal tibia. This amount should correspond to the thickness of the prosthesis. It relies on anatomical landmarks to determine the placement of the prosthetic components. Femoral and tibial preparations usually are performed independently using measured resection. Once the bony cuts have been made trial prostheses are inserted. Then the knee is tested in flexion and extension when ligaments are released to correct gap asymmetry and ligament tightness.

Now trial component was removed and prosthesis placed and fixed to bone. First the femoral component with help of one packet of cement, then the tibial component using another packet of cement, was fixed. Tourniquet deflated and hemostasis was achieved. Wound washing with normal saline and closure was done in layers with knee in extension under negative suction drain.

\section{Results}

The mean preoperative Knee Society Knee Score was 23.2 points and improved to 86 points in the cohort group at the follow-up, indicating very good overall results. The range of motion improved from $67.3^{\circ}$ to 121.95 , enabling the patients to stand up from a sitting position. Complications were seen in 3 cases, and were pain, deep vein thrombosis and respiratory infection in one month post operative period.

12 month follow up showed one knee to have asymptomatic radiolucent lines.

Varus knee deformity is very well corrected when the total knee arthroplasty is done with the

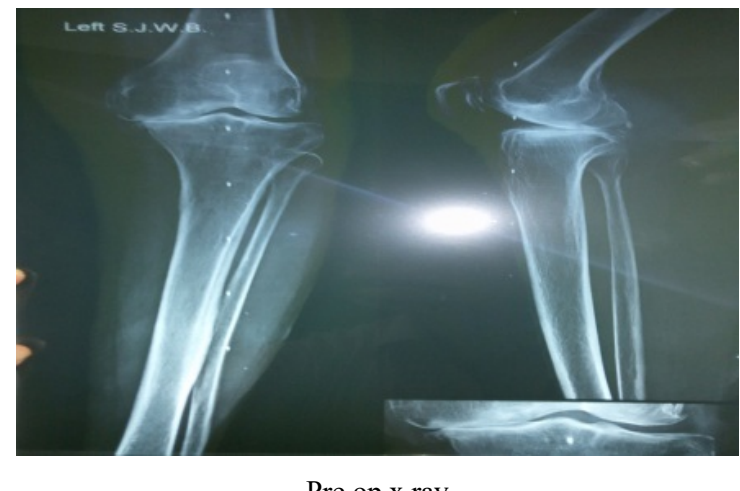

Pre op x ray 


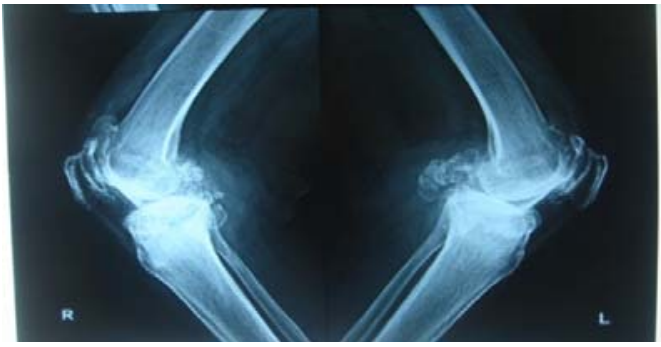

Pre op weight bearing $\mathrm{x}$ ray ap view

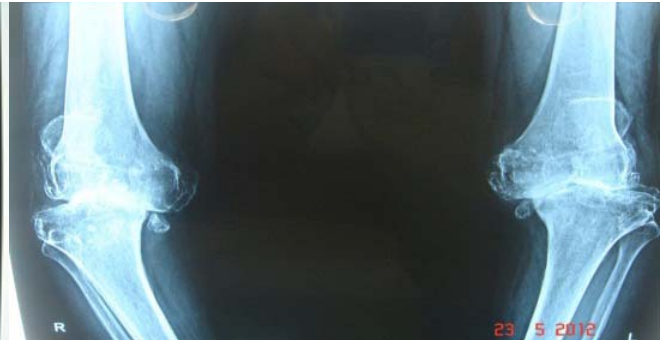

pre op x ray lateral view

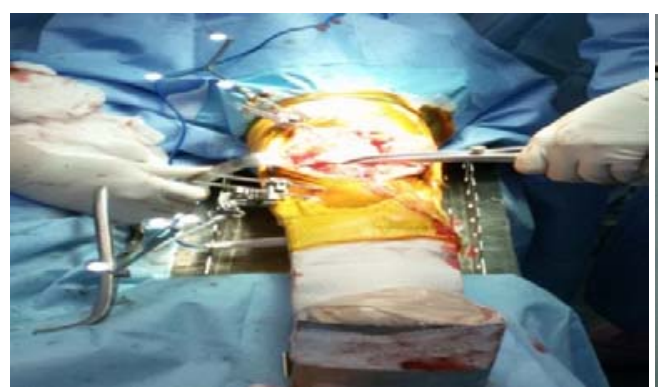

Full correction of varus deformity

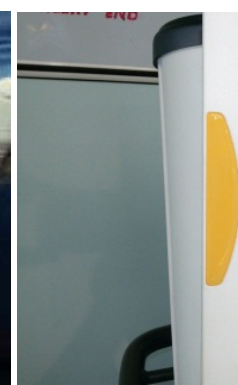

intra op full correction of deformity
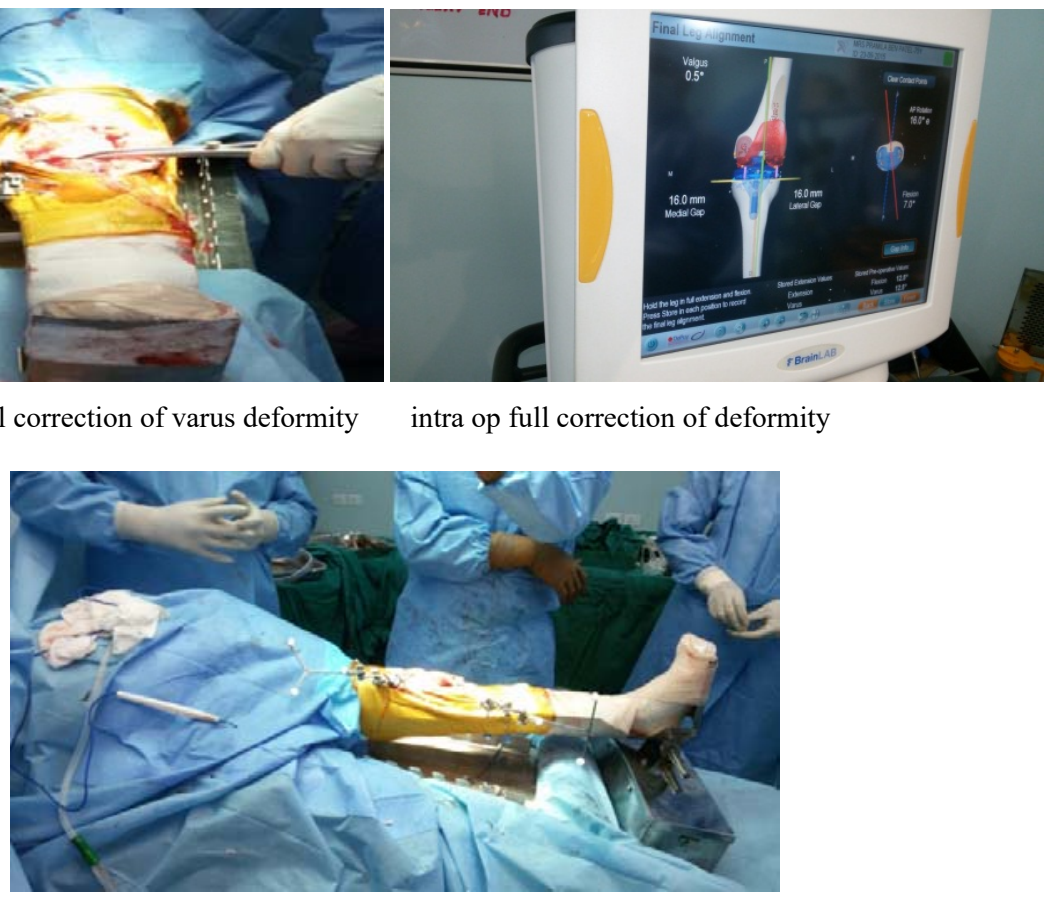

Intra op full correction of deformity

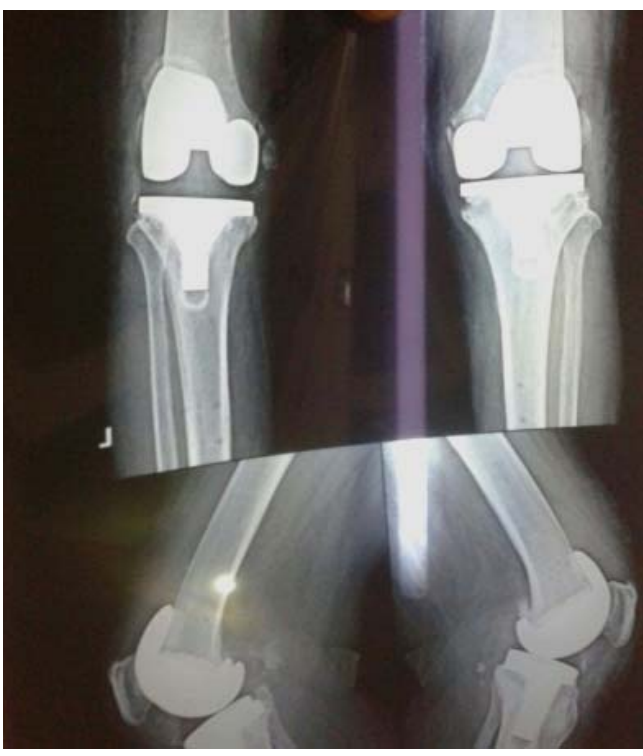

Follow up X-ray

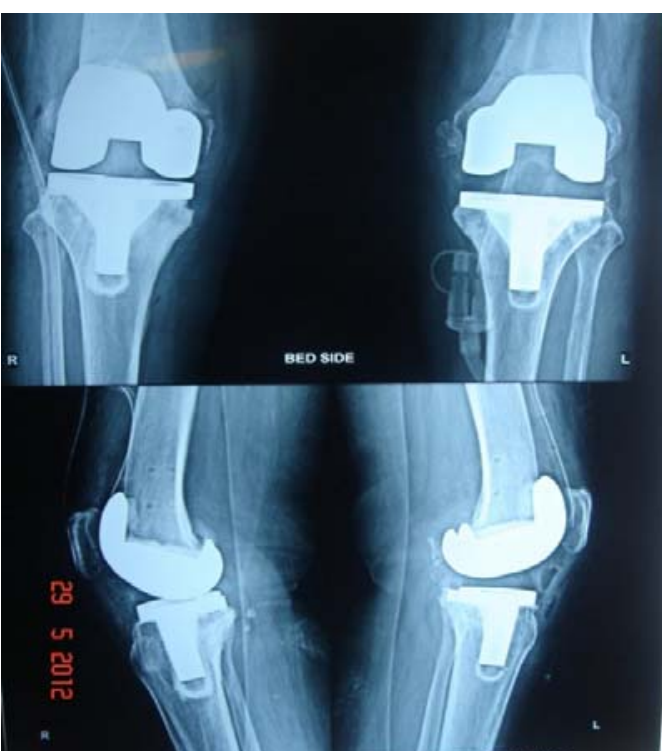

post op $\mathrm{x}$ ray AP and Lateral View 


\section{CASE I}
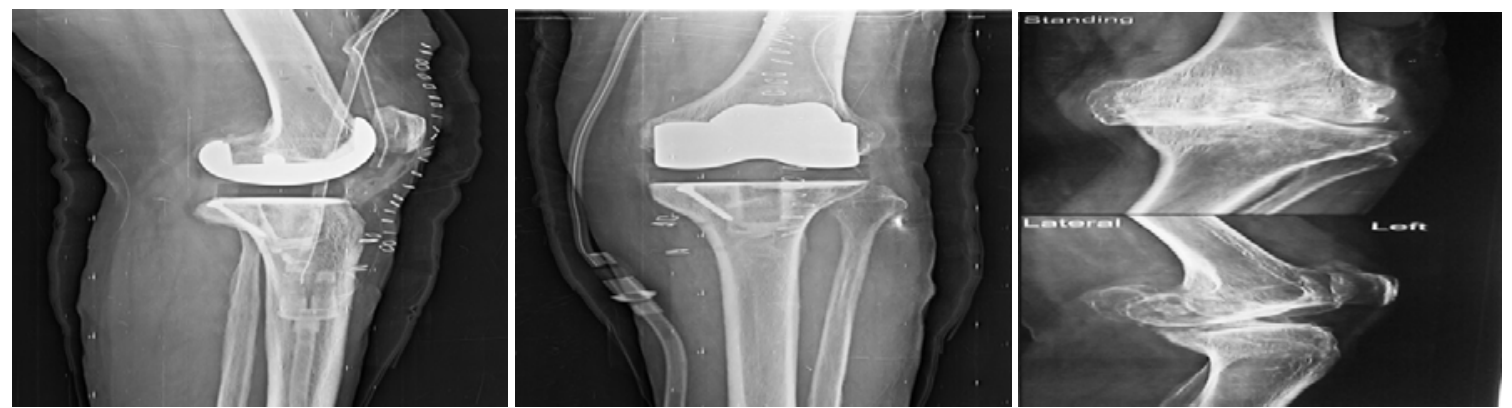

CASE II
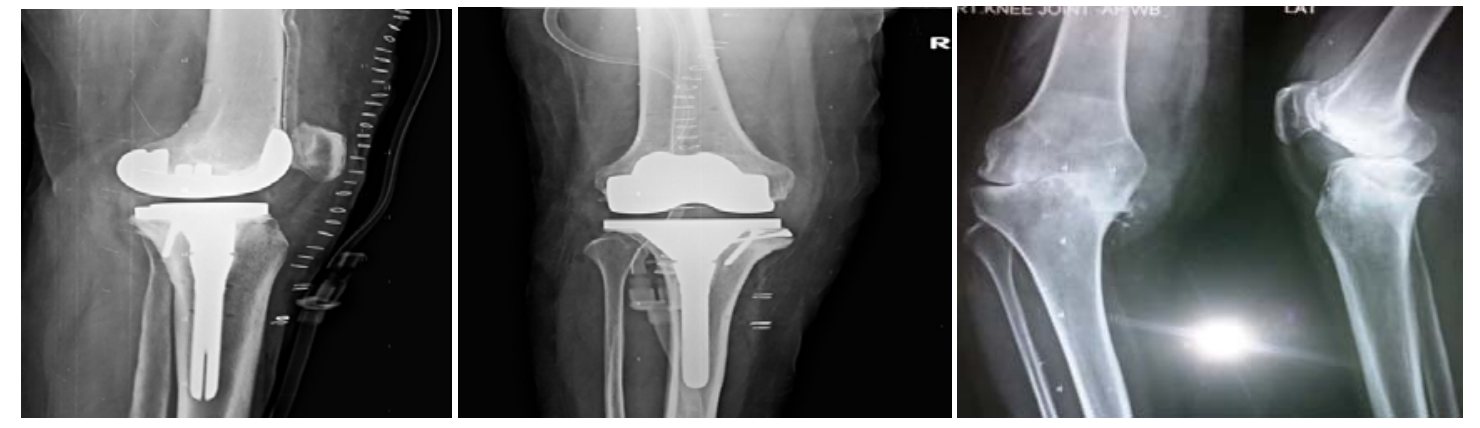

CASE III
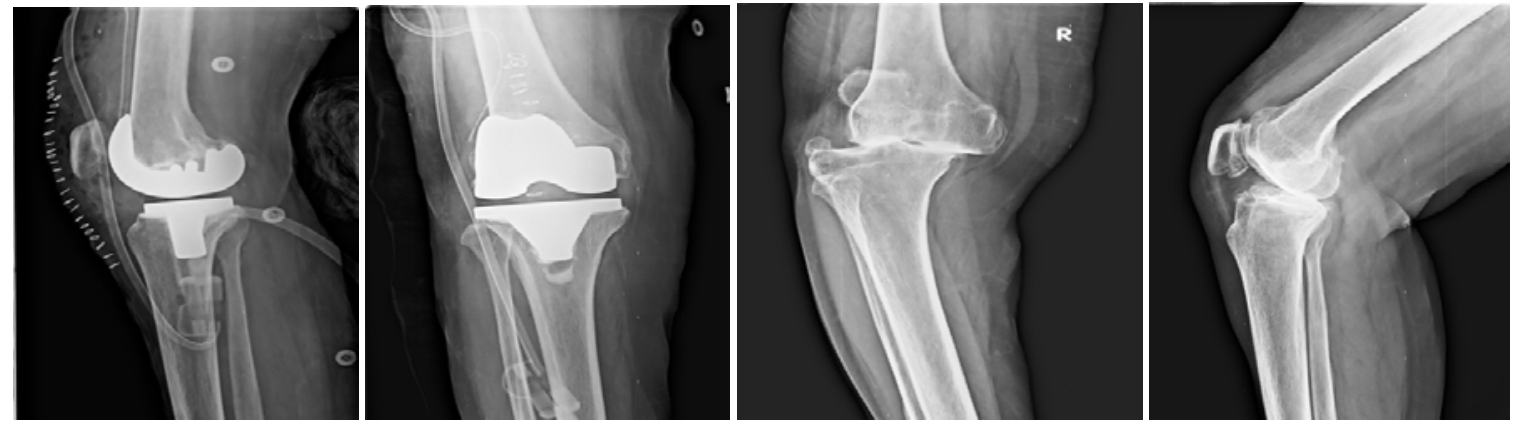

CASE IV

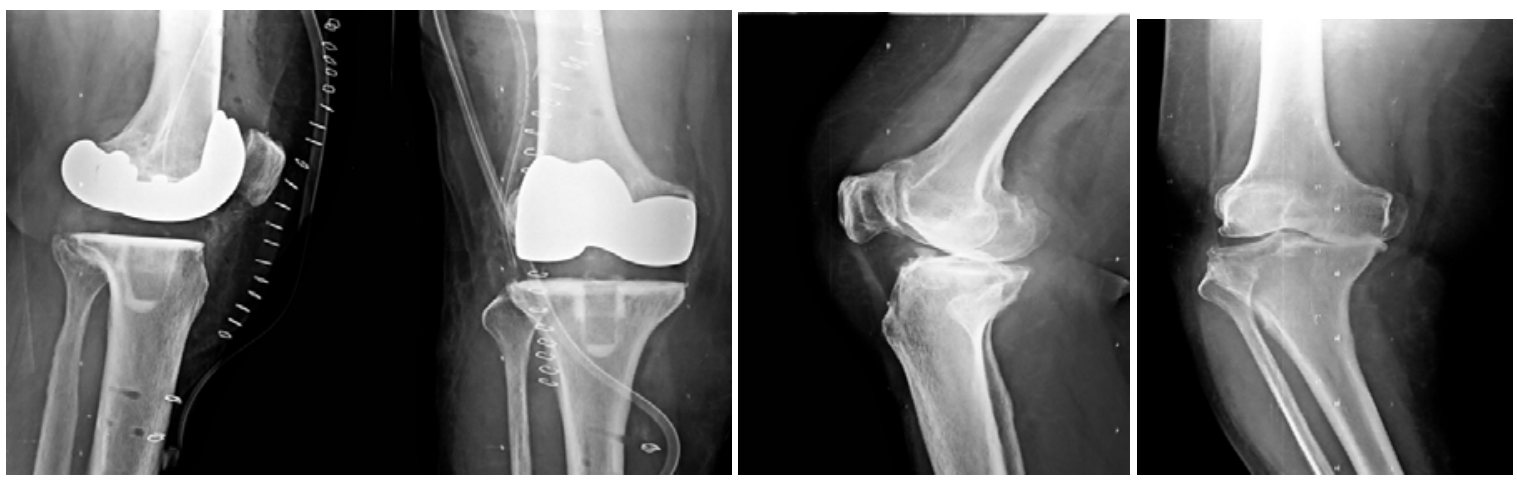

We applied unpaired $t$ test for the evaluation of the results and two tailed $\mathrm{p}$ value was considered the criteria for statitical significance 
Table 1

\begin{tabular}{|c|c|c|c|}
\hline \multirow{2}{*}{ Post operative period } & \multicolumn{2}{|c|}{ Mean Knee ROM } & \multirow{2}{*}{ p-value } \\
\cline { 2 - 3 } & With navigation & Without navigation & NA \\
\hline Pre operative & $67.3^{0}$ & $66.5^{0}$ & 0.0002 \\
\hline 1 month & $88.85^{0}$ & $80.3^{0}$ & 0.0001 \\
\hline 3 month & $107^{0}$ & $92.45^{0}$ & 0.0001 \\
\hline 6 month & $116.55^{0}$ & $101^{0}$ & 0.0001 \\
\hline 1 year & $121.95^{0}$ & $105.9^{0}$ & \\
\hline
\end{tabular}

The $\mathrm{p}$ values and hence the results at 1,3,6 months and 1 year follow up for mean knee range of motion are extremely statistically significant.

Table 2

\begin{tabular}{|c|c|c|c|}
\hline \multirow{2}{*}{ Post operative period } & \multicolumn{2}{|c|}{ Mean Tibio femoral angle (varus) } & \multirow{2}{*}{ P-value } \\
\cline { 2 - 3 } & With navigation & Without navigation & \\
\hline Pre operative & $16.40^{0}$ & $16.55^{0}$ & NA \\
\hline Immediate post operative & $0.15^{0}$ & $1.15^{0}$ & 0.2334 \\
\hline
\end{tabular}

The $\mathrm{p}$ values and hence the results at 1,3,6 months and 1 year follow up for Mean Tibio femoral angle (varus) are not statistically significant.

Table 3

\begin{tabular}{|c|c|c|c|}
\hline \multirow{2}{*}{ Post operative period } & \multicolumn{2}{|c|}{ Mean Fixed Flexion Deformity } & \multirow{2}{*}{ P value } \\
\cline { 2 - 3 } & With navigation & Without navigation & \\
\hline 1 month & $7.35^{0}$ & $8.95^{0}$ & 0.0428 \\
\hline 3 month & $5.3^{0}$ & $6.55^{0}$ & 0.0399 \\
\hline 6 month & $4.5^{0}$ & $5.8^{0}$ & 0.0129 \\
\hline 1 year & $3.3^{0}$ & $4.85^{0}$ & 0.0150 \\
\hline
\end{tabular}

The $\mathrm{p}$ values and hence the results at 1,3,6 months and 1 year follow up for mean fixed flexion deformity are statistically significant.

Table 4

\begin{tabular}{|c|c|c|c|}
\hline \multirow{2}{*}{ Post operative period } & \multicolumn{2}{|c|}{ Mean Knee Society Knee Score } & \multirow{2}{*}{ P value } \\
\cline { 2 - 3 } & With navigation & Without navigation & \\
\hline Pre operative & 23.2 & 23.8 & NA \\
\hline 1 month & 71.15 & 68.55 & 0.0470 \\
\hline 3 month & 77.95 & 70.30 & $<0.0001$ \\
\hline 6 month & 84.05 & 77.95 & $<0.0001$ \\
\hline 1 year & 84.45 & 83.00 & 0.0270 \\
\hline
\end{tabular}

The $\mathrm{p}$ values and hence the results at 1 month and 1 year follow up for mean knee society knee score are extremely statistically significant.
The $\mathrm{p}$ values and hence the results at 3 and 6 months follow up for mean knee society knee score are statistically significant.

Table 5

\begin{tabular}{|c|c|c|c|}
\hline \multirow{2}{*}{ Post operative period } & \multicolumn{2}{|c|}{ Mean Knee Society Function Score } & \multirow{2}{*}{ P value } \\
\cline { 2 - 3 } & With navigation & Without navigation & \\
\hline Pre operative & 21 & 21.25 & NA \\
\hline 1 month & 69.50 & 65.25 & 0.3025 \\
\hline 3 month & 87.75 & 86.50 & 0.6978 \\
\hline 6 month & 97.75 & 96.75 & 0.2953 \\
\hline 1 year & 98.50 & 97.50 & 0.2513 \\
\hline
\end{tabular}

The $\mathrm{p}$ values and hence the results at 1,3,6 months and 1 year follow up for mean Knee Society Function Score are not statistically significant. 


\section{Discussion}

Several technical requirements during TKA are important to obtain good results:

- correction of deformities;

- achievement of functional joint motion and stability;

- optimal balancing of soft tissues;

- Satisfactory alignment in the frontal, sagittal and horizontal planes.

\section{Massive Varus-Challenges \\ 1. Anatomical Alignment}

Historical literature showed that neutral mechanical alignment (HKA $180^{\circ}$ ) with outliers within three degrees was the best guarantee for long-term survival of a TKR ${ }^{[16]}$. From literature data alignment in frontal plane must be into $2^{\circ}$ or $3^{\circ}$ range around a neutral alignment; this thought is demonstrated by Ritter at al who observed that prostheses implanted in varus position had a lower survival rate than prostheses implanted in a neutral or valgus position ${ }^{[17]}$. Jeffery at al observed that when mechanical axis was in $3^{\circ}$ valgus-varus range, the loosening rate was $3 \%$, whereas it's $24 \%$ when the alignment was out of this range ${ }^{[18]}$.

\section{Ligament Balancing}

The arthritic process leading to a total knee replacement causes joint deformity and osteophytes. This joint deformity can cause both irreversible ligament shortening on the collapsed side and elongated ligaments on the convex side. Osteophytes can cause tightness by tenting the ligaments resulting in restriction of movement and flexion contractures ${ }^{[19]}$. Ligament balancing attempts to counter these changes. This is achieved usually by removing osteophytes and lengthening and dissecting tight ligaments in sequence. Tightening lax ligaments, albeit more difficult and rarely used, also can play a role ${ }^{[20,21]}$.

A balanced knee has many postoperative advantages, and this is supported by the literature, although randomized control studies of ligament balancing are limited ${ }^{[19,22-24]}$.

Ligament balancing has been shown to be important in producing better limb alignment ${ }^{[22]}$. A series of normally aligned knees that went on to develop early medial insert wear progressing to varus malalignment pointed toward inadequate medial compartment ligament balancing as a possible cause ${ }^{[25]}$. Ligament balancing is a recognized key determinant of postoperative stability [26-28], and has been described as a possible preventable cause of the $27 \%$ of early knee revisions owing to instability ${ }^{[29]}$.

\section{Deficient Bone stock}

Bone deficiencies are frequently encountered during TKR in cases of severe varus deformities. The method used to compensate for a given bone defect depends on the size and the location of the defect.

Rand classified these defects which is also very useful for deciding the management of these defects.

Contained defects can be filled with small cancellous bone grafts whereas larger defects may require metal wedges or screws with cement/bone graft. The use of screw with cement is demonstrated in two cases in our study (case 1 and case 2).

\section{Conclusion}

In our study, Computer assisted total-knee arthroplasty gave excellent to good result in terms of clinical and radiological parameters and good functional outcome with a minimun follow up period of 12 months.
Majority of studies show that navigated TKR decreases the malalignment of the mechanical limb axis compared with conventional TKR. Whether this marginal benefit makes any significant difference in long term outcome of the patient needs follow up studies equal to the studies done on conventional TKR. The technology of navigation, though appears promising in complex primary like severe varus deformities.

It is important to realise that conventional techniques in TKR surgery have resulted in high prosthesis survival rate lasting up to 15-20 years. As the CAS has survived its infancy, it is therefore important that functional and clinical outcomes be collected on a regular basis in order to elucidate the role of it. Hence, further multicentre randomised controlled clinical trials comparing conventional TKR with CAS need to be undertaken with long follow up to demonstrate better clinical and functional outcomes, lesser complication rate along with cost effectiveness of the CAS procedure over conventional primary TKR surgery to make it universally acceptable.

\section{References}

1. Li CS, Karlsson J, Winemaker M, Sancheti P, Bhandari M. Orthopedic surgeons feel that there is a treatment gap in management of early OA: international survey. Knee Surg Sports Traumatol Arthrosc, 2013. Doi 10.1007/s00167-013-2529-5.

2. Guillemin F, Rat AC, Mazieres B, Pouchot J, Fautrel B, Euller-Ziegler L et al. Prevalence of symptomatic hip and knee osteoarthritis: a two-phase population-based survey. Osteoarthritis Cartilage. 2011; 19:1314-22.

3. Ackerman IN, Osborne RH. Obesity and increased burden of hip and knee joint disease in Australia.

4. Buechel FF. Long term follow up after mobile-bearing total knee replacement. Clin Orthop Relat Res, 2002; 404:40. ISSN 1528-1132

5. Robertsson O, Knutson K, lewold S et al. The Swedish knee arthroplasty register 1975-1997: an update with special emphasis on 41,223 Knees operated on in 19881997. Acta Orthop Scand, 2001; 72(5):503-13. ISSN 0001-6470

6. Jeffery R, Morris R, Denham R. Coronal alignment after total knee replacement. J Bone Joint Surg Br, No.5, September 1991; 73:709-14, ISSN:0301-620X.

7. Rand JA, Coventry MB. Ten years evaluation of geometric total knee arthroplasty. Clin Orthop Relat Res, 1988; 232:168-73, ISSN 1528-1132.

8. Bäthis H, Perlick L, Tingart M, Lüring C, Zurakowski D, Grifka J. Alignment in total knee arthroplasty. A comparison of computer-assisted surgery with the conventional technique. J Bone Joint Surg Br, 2004; 86(5):682-7. ISSN:0301-620X

9. Fehring TK, Mason JB, Moskal J, Pollock DC, Mann J, Williams VJ. When computerassisted knee replacement is the best alternative. Clin Orthop Relat Res. 2006; 452:132-6, ISSN 1528-1132.

10. Berman AT, Parmet JL, Harding SP, Israelite CL, Chandrasekaran K. Emboli observed with use of transesophageal echocardiography immediately after tourniquet release during total knee arthroplasty with cement. J Bone Joint Surg Am, 1998; 80(3):389-94, ISSN 1535-1386.

11. Ritter MA, Faris GW, Faris PM, Davis KE. Total knee arthroplasty in patients with angular varus or valgus deformitiesof $>$ or $=20$ degrees. J Arthroplasty. 2004; 19(7):8626. 
12. Mullaji AB, Padmanabhan V, Jindal G. Total knee arthroplasty for profound varus deformity: technique and radiological results in 173 knees with varus of more than 20 degrees. J Arthroplasty. 2005; 20(5):55061.

13. De Muylder J, Victor J, Cornu O et al. Total knee arthroplasty in patients with substantial deformities using primary knee components. Knee Surg Sports Traumatol Arthrosc. 2015; 23:3653.

14. Insall JN, Ranawat CS, Aglietti P, Shine J. A comparison of four models of total knee-replacement prostheses. J Bone Joint Surg (Am) 1976; 58(6):754-765

15. Insall JN, Dorr LD, Scott RD, Scott WN. Rationale of the Knee Society clinical ratingsystem. ClinOrthop. 1989; (248):13-14.

16. Fang DM, Ritter MA, Davis KE. Coronal alignment in total knee arthroplasty: just how important is it? J Arthroplasty. 2009; 24:39-43.

17. Ritter MA, Faris PM, Keating EM, Meding JB. Postoperative alignment of totalknee replacement. It's effect on survival. Clin Orthop Relat Res, 1994; 299:153156, ISSN 1528-1132.

18. Jeffery R, Morris R, Denham R. Coronal alignment after total knee replacement. J Bone Joint Surg Br, 1991; 73(5):709-14, ISSN: 0301-620X.

19. Whiteside LA. New York: Springer; Ligament balancing in total knee arthroplasty: an instructional manual, 2004.

20. Tria AJ. Jr. Management of fixed deformities in total knee arthroplasty. J Long Term Eff Med Implants. 2004; 14:3350.

21. Favorito PJ, Mihalko WM, Krackow KA. Total knee arthroplasty in the valgus knee. J Am AcadOrthop Surg. 2002; 10:16-24.

22. Sharkey PF, Hozack WJ, Rothman RH et al. Insall Award paper. Why are total knee arthroplastiesfailingtoday? ClinOrthopRelat Res. 2002; 404:7-13.

23. Insall JN. New York: Churchill Livingstone; Surgery of the knee, 1984.

24. Unitt L, Sambatakakis A, Johnstone D et al. Shorttermoutcome in total knee replacement after soft tissue release and balancing. J Bone Joint Surg Br. 2008; 90:159-65.

25. Wasielewski RC, Galat DD, Komistek RD. Correlation of compartment pressure data from an intraoperative sensing device with postoperative fluoroscopic kinematic results in TKA patients. J Biomech. 2005; 38:333-9.

26. Fehring TK, Valadie AL. Knee instability after total knee arthroplasty. Clin Orthop Relat Res. 1994; 299:157-62.

27. Miyasaka KC, Ranawat CS, Mullaji A. 10to20yearfollowup of total knee arthroplasty for valgus deformities. Clin Orthop Relat Res. 1997; 345:29-37.

28. Takahashi T, Wada Y, Yamamoto H. Softtissuebalancing with pressure distribution during total kneearthroplasty. J Bone Joint Surg Br. 1997; 79:235-9.

29. Fehring TK, Odum S, Griffin WL et al. Early failures in total knee arthroplasty. Clin Orthop Relat Res. 2001; 392:315-8. 